proposto por Odent indica a importância de que os/as acompanhantes sejam preparados com informações e sensibilização para a experiência. Além disso, as equipes obstétricas e pediátricas precisam ser treinadas para lidar com a família e a profundidade emocional do nascimento. A colocação dessa questão por Odent nos remete ao desafio para a sua proposta de abordagem ecológica do nascimento em que a aliança entre cultura e natureza deverá estar sempre presente.

Odent é um cientista revolucionário e um visionário da construção do que ele chama de era do Homo ecologicus, em que o cuidado com a vinculação entre a mãe e o bebê no período em torno do nascimento possibilitará o desenvolvimento de uma sociedade voltada para o amor, onde o respeito ao outro e à natureza estejam presentes. A leitura de suas obras, sem dúvida alguma, é um grande estímulo para que cada um de nós, profissionais, mães e pais, receba as próximas gerações com mais amor.
${ }^{1}$ Ver http:// primalhealth.com.

${ }^{2}$ Esse questionamento sobre a participação dos pais no parto está presente em A cientificação do amor, no prefácio da segunda edição americana de $O$ renascimento do parto e no artigo Is the Participation of the Father Prejudicial to the Birth?, publicado na Internet em http://wwwçmidwiferytoday.com/fathers/ waterfamily, em 18 de abril de 2001.

${ }^{3}$ BERTSCH T. D., NAGASHIMA-WHALEN, L., DYKEMAN, W., KENNELL J. H., and MACGRATH, S. "Labor Support by FirstTime Fathers: Direct Observations with a Comparison to Experienced Doulas". Journal of Psychosomatic Obstetric Ginaecology, II, 1990, 251-260. CARVALHO, Maria Luiza Mello de. A participação do pai no nascimento da criança: as famílias e os desafios institucionais em uma maternidade pública. 2001. Dissertação (Mestrado em Psicossociologia de Comunidades e Ecologia Social) Universidade Federal do Rio de Janeiro.

${ }^{4}$ CARVALHO, 2001.

MARIA LUIZA DE CARVALHO

Universidade Federal do Rio de Janeiro

\title{
Que valores escolhemos nesse ritual?
}

\author{
Birth as an American Rite of \\ Passage.
}

DAVIS FLOYD, Robbie.

Berkeley: University of California Press, 1992. $382 \mathrm{p}$.

A irracionalidade das práticas da assistência ao parto - a contradição entre o que prescreve a ciência e como as práticas se organizam - tem intrigado muitos estudiosos do tema há várias décadas. Para iluminar esse enigma, além dos movimentos sociais organizados e daqueles que lidam com a medicina perinatal, surge a contribuição de antropólogas que vieram a compor o que hoje se conhece como a 'Antropologia do Parto', criada em torno do trabalho inovador de várias autoras, entre elas Brigitte Jordan, chamada a 'parteira' desse campo. Jordan desenvolveu um estudo comparativo sobre o parto em quatro culturas e incluiu o modelo norte-americano de assistência como um deles, de maneira a analisá-lo como fenômeno antropológico da mesma forma que - 'modelo' de outras culturas, 'complexas' ou 'primitivas', criando um estranhamento sobre a assistência norte-americana até então inédito.'

Para uma revisão exaustiva do tema há, entre outras, a coletânea de Robbie Davis-Floyd e Carolyn Sargent, ${ }^{2}$ um extenso levantamento do tema na literatura antropológica. Nos poucos anos que se passaram depois dessa coletânea, houve um número crescente de estudos sobre parto no mundo inteiro, inclusive no Brasil. Esses trabalhos, partindo de diversas bases conceituais e disciplinares, têm muitas vezes procurado o diálogo e a interfecundação na abordagem do seus objetos.

Entre os trabalhos mais provocativos para essa interfecundação está o da antropóloga cultural Robbie Davis-Floyd, e em especial o seu livro Birth as an American Rite of Passage (1992). Essa obra pode ser abordada de muitas maneiras. Como médica, com formação em Medicina Preventiva, prefiro abordá-lo da perspectiva do diálogo - e das provocações - 
que traz para as nossas reflexões e intervenções no campo da Saúde Coletiva no Brasil, e para o movimento por mudança nas práticas de assistência ao parto.

A partir de mais de cem entrevistas com mulheres de classe média e profissionais de saúde nos Estados Unidos, a autora explora as experiências pessoais desses personagens em relação ao parto e sua 'formatação cultural'. Ela parte do reconhecimento de que todas as sociedades humanas canalizam o processo de nascer para ritos de passagem, que têm a marca dos valores que essa sociedade partilha. Uma das contribuições mais inovadoras do texto é demonstrar que, diferentemente do que costumamos pensar, a transferência do local de parto da casa para o hospital não representou uma des-ritualização daquilo que em outras sociedades ditas primitivas foi sempre um processo carregado por superstições e tabus. Pelo contrário, a transferência do parto para o hospital "resultou na mais elaborada proliferação de rituais em torno deste evento fisiológico já vista no mundo cultural humano" (p. 2).

No seu estudo, Davis-Floyd toma como referência não apenas a literatura antropológica sobre os rituais e sobre o parto, mas também recupera a contribuição de muitas outras autoras feministas e do movimento de saúde das mulheres, pois considera que "a revisão feminista sobre o parto, como apresentada nesses trabalhos, tem um valor e poder imensos" (p. 5).

Ela descreve um ritual com a encenação (enactment, que tem o duplo sentido de atuação e de decreto) padronizada, repetitiva, simbólica e transformativa de uma crença ou valor cultural, cujo principal objetivo seria 0 alinhamento do sistema de crenças do indivíduo com o da sociedade. Um rito de passagem consistiria em uma série de rituais através dos quais as pessoas são transportadas de um status social para outro, desse modo transformando tanto a maneira como a sociedade o define quanto como o indivíduo define a ele mesmo. Esse processo transformativo exigiria experiências fora do comum, incluindo dificuldades e desafios físicos e mentais, cujo enfrentamento facilitaria a ruptura com o estado anterior e a abertura psicológica dos iniciados nos novos papéis.

A partir dessa perspectiva, Davis-Floyd analisa as maneiras pela quais os sistemas de valores e crenças norte-americanos (especialmente o lugar da ciência e da tecnologia, e das instituições que as disseminam e controlam) se expressam e se perpetuam nos rituais em torno do parto hospitalar. Ela busca dissecar, nesses rituais que chamamos 'procedimentos da assistência', seu simbolismo, sua matriz cognitiva, o padrão repetitivo, a desestruturação e estabilização cognitiva, o senso de inevitabilidade, o caráter dramático e sua intensificação, o compromisso com o status quo, e mesmo suas contradições e paradoxos.

No capítulo sobre as mensagens do parto, a autora nos convida a uma análise simbólica de cada uma das rotinas padronizadas na assistência norte-americana. Quase nada escapa ao seu olhar provocador que chama $o$ leitor ao estranhamento diante das condutas, analisadas quanto a sua descrição oficial e justificativa, aos efeitos fisiológicos, às respostas das mulheres e aos seus objetivos rituais. Assim ela percorre as rotinas: o uso da cadeira de rodas para a admissão da parturiente, a separação da família, a troca das roupas pelas batas abertas do hospital, a lavagem retal, a permanência no leito e a limitação de movimentos, a privação de comida e de água, o uso de soro na veia, o uso de ocitocina para aumentar as contrações, o rígido controle de tempos e movimentos, os usos da analgesia e anestesia, a ruptura das membranas, o monitoramento fetal interno e externo, os toques vaginais, as orientações de quando fazer ou não fazer força, a transferência do pré-parto para a sala de parto, a posição deitada, com as pernas para cima e imobilizadas, o uso de panos cirúrgicos estéreis, de mãos atadas, de máscaras e de desinfetantes; e por fim a episiotomia (corte da vulva e vagina) - e ainda os procedimentos do pós-parto e da assistência ao bebê.

É importante lembrar que o livro, publicado há dez anos, já se remete ao questionamento interno à própria medicina sobre a extrema variabilidade geográfica do que seria a "assistência adequada" e sobre quais seriam as bases científicas das rotinas utilizadas. A partir da segunda metade da década de 1980, muitos grupos de profissionais passam a se organizar para sistematizar os estudos de eficácia e segurança na assistência à gravidez, ao parto e ao pós-parto, iniciando um esforço que se estendeu mundialmente, apoiado pela Organização Mundial da Saúde,$^{3}$ e que revolucionou o que hoje chamamos de assistência adequada.

A avaliação científica das práticas na década de 1990 vem postulando a efetividade 
e a segurança de uma atenção ao parto com um mínimo de, ou nenhuma, intervenção sobre a fisiologia e a adoção de muitos procedimentos centrados nas necessidades das parturientes ao invés de organizados em função das necessidades das instituições e profissionais. Tratase de uma mudança de paradigma que redimensiona totalmente a sentido da assistência. Entender os componentes dessa assistência em sua dimensão simbólica, como rituais, se torna ainda mais relevante hoje do que era há uma década.

Para nós, profissionais de saúde, um dos obstáculos à comprensão dessas dimensões rituais e simbólicas do parto está justamente na nossa dificuldade de transpor a crença 'religiosa' que temos na racionalidade da técnica. Como escreve Davis-Floyd, à medida que cresce e se acumula a evidência de que os procedimentos médicos habituais na assistência ao parto são muitas vezes desnecessários e mesmo danosos, "muitos indivíduos envolvidos com o tema se perguntam como uma prática que se propõe tão científica pode ser tão irracional" (p. 2). Ou como nos informa uma médica brasileira, conhecedora das pesquisas sobre essas evidências: "Racionalmente, eu sei que não é pra fazer a episiotomia. Mas a minha mão vai sozinha". ${ }^{4}$ Nós nos perguntamos: se sabemos que as rotinas não são inocentes, por que é tão penoso mudar?

Para a autora, os procedimentos obstétricos tenderiam a permanecer, independentemente de sua efetividade, de sua segurança ou do sofrimento que provocam, por serem "respostas rituais racionais para o medo extremo, em nossa sociedade tecnocrática, dos processos naturais dos quais esta sociedade depende para continuar sua existência" (p. 2-3). Abaixo daremos alguns exemplos dessa re-leitura sobre os procedimentos, que ajuda a nós, que os executamos, a enxergá-los com novos olhos sob nossas pálpebras velhas.

Sobre a episiotomia e sua permanência, por exemplo, mostra, através dos depoimentos de usuárias e provedores, em que medida "os médicos, como representantes da sociedade, podem desconstruir a vagina (e por extensão, suas representações), para então reconstruí-la de acordo com nossas crenças culturais e sistema de valores" (p. 129). A mensagem é que as mulheres não são capazes de dar à luz as crianças sem a tecnologia, que resgataria mãe e filho dos riscos e seqüelas do parto.

Nesse trabalho, a exploração dos vínculos entre a 'sexualidade' e a 'reprodução' aparece como uma tarefa fundamental, compreendendo o parto como uma função sexual normal das mulheres, em uma linha em que a autora recupera o trabalho de, ${ }^{5}$ entre outras. Para DavisFloyd, um dos mais importantes dilemas da assistência - e sua crença na superioridade da tecnologia sobre o corpo - é remover a sexualidade do processo de parir, pois tudo na cena do parto é referido à sexualidade - suas secreções e gemidos, sua corporalidade, a gestação como resultado de uma relação sexual e mesmo os genitais expostos e manipulados. "Hoje, a sexualidade se mantém como uma potente ameaça conceitual aos poderes criativos da tecnologia, e a sexualidade feminina se mantém como a principal lembrança dessa ameaça" (p. 69).

Ainda hoje persiste, apesar das evidências de ser na maioria das vezes muito dolorosa além de arriscada, a rotina da administração de ocitócitos para acelerar o parto, através do 'vínculo umbilical' do soro intravenoso, prendendo a mulher à instituição e a 'nutrindo' com o medicamento. Essa permanência teria também como finalidade comunicar à mulher a superioridade do nosso conceito cultural de tempo como linear, mensurável e associado à produtividade, e o tempo profissional como mercadoria valiosa - enfim, a superioridade das necessidades da instituição sobre as da mulher. Comunica também que o corpo da mulher deveria funcionar como uma máquina e, se não está produzindo sozinho as reações consideradas adequadas à produtividade institucional (contrações, dilatação), esse corpo é uma máquina defeituosa, cujo ritmo deve ser corrigido, e submetido ao das instituições e profissionais. $O$ aumento (e eventual insuportabilidade) da dor resultante da ocitocina "serviria aos objetivos rituais de enevoar, atordoar - isso é, de acelerar a ruptura do iniciado com seu sistema prévio de valores, através da intensificação da tensão física" (p. 98-99).

Uma versão revista do capítulo sobre a análise cultural das mensagens do parto e seus procedimentos de rotina se transformou em um dos mais lindos sites da constelação de recursos eletrônicos sobre o tema, o http:// www.birthpsychology.com/messages/. O livro tem ainda vários capítulos que lidam com temas tais como a discussão sobre os modelos tecnocrático, humanístico e o holístico, o treinamento dos médicos como rito de passagem, e outros temas 
de grande atualidade que a autora vem retomando nos anos mais recentes.

Davis-Floyd, uma pesquisadora com uma carreira acadêmica muito produtiva e respeitada, pode causar estranhamento com o seu gosto (ainda mais presente nos trabalhos recentes) por temas tais como o modelo holístico de assistência, dimensões espirituais do cuidado, o papel da intuição no conhecimento, ou por um certo romantismo e idealização do trabalho das parteiras. Alguns autores criticam sua abordagem excessivamente sistêmica, pouco adequada para perceber as nuances, tensões e contradições do modelo tecnológico e sua interação com as mulheres. Ou ainda uma dificuldade de perceber até que ponto a técnica em si (os procedimentos) não seria uma expressão dos valores que estão sendo questionados, ao invés de esferas separadas - de um lado a ideologia e do outro a neutralidade técnica. Ou mesmo fazem reparos ao que identificam como uma tendência - apesar dos cuidados da autora nesse sentido - a sugerir que o projeto de parto ideal (e os valores) dos norte-americanos brancos de classe média seriam generalizáveis a outros contextos sociais. ${ }^{6}$

Se essa generalização é certamente inadequada, devemos também levar em conta que $o$ estudo do que pensam os consumidores de classe média, "fazedores de opinião", sobre o que seria o parto ideal é importante para entender como tais modelos de assistência moldam a percepção do que as demais camadas sociais consideram como desejável mesmo que essa transposição de modelos seja complexa e contraditória, ${ }^{7}$ e que reflita uma estratégia das mulheres mais pobres para fugir da má assistência ao parto vaginal. ${ }^{8}$ Essas questões são todas relevantes, porém em nada diminuem em qualidade a contribuição dessa autora para o atual diálogo sobre a assistência no Brasil - e temos tido o prazer de ouvi-la ao vivo, pois aqui ela encontra muitos interlocutores para as questões que levanta.

O livro de Davis-Floyd nos traz questões fundamentais para o diálogo com os profissionais de saúde, tais como: qual o nosso lugar como profissionais e cuidadores, educados para a intervenção e nela reconhecendo nossa identidade profissional? Qual o nosso papel diante dos questionamentos da eficácia e da segurança de nossas rotinas - para além do nosso papel como oficiantes desses rituais?

Se fomos socializados - como a autora aponta no capítulo 7, em um "tipo de cinismo e arrogância intelectual" resultante da separação entre o conhecimento e percepção do sofrimento, valores esses que devemos absorver em nossa formação antes mesmo de ter contato com os pacientes - como nos portamos diante das 'novas' pacientes, que falam e se movem, querem interação, e mesmo esperam algum envolvimento emocional, alguma compaixão?

Para nós do campo da Saúde Coletiva, que sempre buscamos garantir o acesso das populações mais carentes aos serviços considerados essenciais, entre eles os do prénatal e do parto hospitalar, o livro nos põe diante da responsabilidade de tentar distinguir o que seria o caráter ritual da assistência e as condutas de fato seguras e efetivas - e mesmo a necessidade da convivência incômoda com a falta de certezas. Recoloca o debate acerca da maternidade segura: não há a priori nenhuma incompatibilidade, mas os serviços que associem segurança, efetividade e respeito aos direitos (mais ou menos o que temos chamado por aqui de 'humanizados') ainda estão em construção.

Para o movimento de mulheres, o trabalho de Davis-Floyd aponta para a necessidade de devolver ao parto e à reprodução sua dimensão erótica. $E$ também, já que se trata de rituais, de pensar ritos mais ricos, mais significativos, mais satisfatórios, mais inclusivos, a partir da nossa diversidade como mulheres. Sim, nos coloca novas responsabilidades, uma vez que costumamos pensar o parto como mais uma ocasiáo de passividade e de entrega do corpo para o Outro. Quem queremos que presencie, ou que oficie esses ritos, como, onde, por quê? Enfim, a principal provocação parece ser: nesse momento de passagem, que valores queremos partilhar e transmitir?

\footnotetext{
1 JORDAN, BRIGITTE. Birth in Four Cultures: A Cross-Cultural Investigation in Yucatán, Holland, Sweden and the United States. 4nd ed. Prospect Heights, III. Waveland Press, 1979. 2 Davis Floyd, Robbie, and Sargent, Carolyn. (eds.). Childbirth and Authoritative Knowledge: Cross-Cultural Perspectives. Berkeley: University of California Press, 1997. ${ }^{3}$ World Health Organization. Care in Normal Birth: A Practical Guide. Maternal and Newborn Health/Safe Motherhood Unit. Geneva: WHO, 1996. cochrane colaboration. www.cochraneconsumer.com/.

${ }^{4}$ DINIZ, Carmen Simone G. Entre a técnica e os direitos humanos: limites e possibilidades das propostas de humanização do parto. 2001. Tese (Doutorado em Medicina Preventiva) - Departamento de Medicina Preventiva da USP, São Paulo. http://www.mulheres.org.br/
} 
parto/.

${ }^{5}$ KITZINGER, SHEILA. "The Sexuality of Birth". In: KITZINGER S. (ed.). Women's Experience of Sex. New York: Penguin, 1985. p. 209-218.

${ }^{6}$ HOTIMSKY, Sonia N. Parto e nascimento no Ambulatório e na Casa de Partos da Associação Comunitária Monte Azul: uma abordagem antropológica. 2001. Dissertação (Mestrado em Saúde Materno-Infantil) - Faculdade de Saúde Pública, USP, São Paulo.

${ }^{7}$ Mello e Souza, Cecilia. "C-sections as Ideal Births: The Cultural Construction of Beneficence in Brazil."
Cambridge Quarterly of Health Care Ethics, v. 3, n. 3, 1994.

${ }^{8}$ BÉHAGUE, Dominique P., VICTORA, Cesar G., and BARROS, Fernando C. "Consumer Demand for Caesarean Sections in Brazil: Population-Based Birth Cohort Study Linking Ethnographic and Epidemiological Methods." British Medical Journal, v.324, p. 942-945, 2002.

SIMONE GRILO DINIZ Universidade de São Paulo
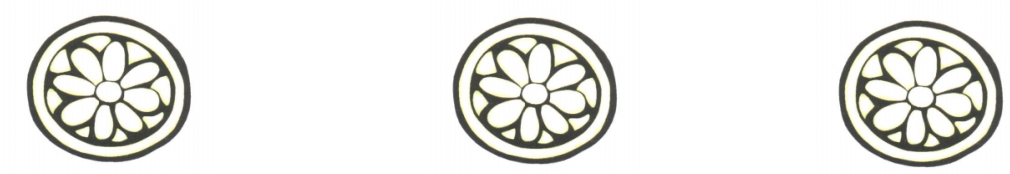

\section{ONDE ENCONTRAR A REVISTA ESTUDOS FEMINISTAS}

\section{LIVRARIAS}

\section{Amapá}

Transa Amazônica Livros

Rua Leopoldo Machado 404

Jesus de Nazaré, Macapá

\section{Amazonas}

Valer Livraria

Rua Ramos Ferreira 1195, Manaus

\section{Ceará}

Livraria Lua Nova

Rua François Teles de Meneses 188/1008

Fortaleza

Minas Gerais

Livraria Liberdade

Rua Santa Rita 545

Juiz de Fora

Livraria Daniel Vaitsman

Rua Espirito Santo 466 Sala 1703, Belo

Horizonte

Pará

Livraria Jinkings

Rua dos Tamoios 1592, Belém

\section{Paraíba}

Lucinha Livraria

UFPB - Campus 1, Bloco CCSA, João Pessoa

Paraná

Editora UFPR

Centro Politécnico - Caixa Postal 19029

81531-990 - Curitiba

\author{
Rio de Janeiro \\ Livraria Argumento \\ Rua Dias Ferreira 417, Leblon, Rio de Janeiro \\ Rio Grande do Norte \\ Potylivros Distribuidora Ltda. \\ Rua Felipe Camarão 609, Natal \\ Rio Grande do Sul \\ Livraria São José \\ Rua Gonçalves Chaves 373, Pelotas \\ Livraria Palmarinca \\ Rua Jerônimo Coelho 281, Porto Alegre \\ Santa Catarina \\ Livraria Insular \\ Rua Tiradentes 204, Florianópolis \\ Livros e Livros \\ Jerônimo Coelho 215, Florianópolis \\ Vitruvius Livraria \\ Curso de Arquitetura - CTC - UFSC, \\ Florianópolis

\section{São Paulo} \\ Futuro Infinito \\ Alameda Franca 1567, Jardins, São Paulo \\ Livraria do IFCH (Instituto de Filosofia e \\ Ciências Humanas) \\ UNICAMP, Campinas, c/ Priscila Aguiar (019) \\ 32890285 \\ Primeira Linha Distribuidora e Livraria \\ Rua Sabará 467, Centro, São Paulo
}

